\title{
Availability of dissolved organic matter offsets metabolic costs of a protracted larval period for Bugula neritina (Bryozoa)
}

\author{
Collin H. Johnson • Dean E. Wendt
}

\begin{abstract}
For nearly a century researchers have investigated the uptake and utilization of dissolved organic matter (DOM) by marine invertebrates, but its contribution to their growth, reproduction, and survival remains unclear. Here, the benefit of DOM uptake was assessed for the marine bryozoan Bugula neritina (Linnaeus 1758) through performance comparisons of individuals in the presence and absence of DOM. The experiments were performed using $B$. neritina collected from floating docks in Beaufort, NC, USA from July to September 2004. Seawater was subjected to ultraviolet irradiation to reduce naturally occurring DOM, and then enriched with either $1 \mu \mathrm{M}$ of palmitic acid or a mixture containing $1 \mu \mathrm{M}$ each of glucose, alanine, aspartic acid and glycine. Larvae in DOM-enriched and DOM-reduced treatments were sampled and induced to metamorphose following 1, 6, 12, and $24 \mathrm{~h}$ of continuous swimming at $25^{\circ} \mathrm{C}$. Sampled larvae were assessed for initiation of metamorphosis, completion of metamorphosis, and ancestrular lophophore size to determine the extent to which energy acquired from DOM uptake could offset the metabolic costs of prolonged larval swimming. DOM treatment had no significant effect on initiation of
\end{abstract}

metamorphosis, but did have a significant effect on completion of metamorphosis and lophophore size. Larvae swimming in DOM-enriched treatments for $24 \mathrm{~h}$ experienced a $20 \%$ increase in metamorphic completion rate, compared to larvae swimming for $24 \mathrm{~h}$ in the DOMreduced treatment. In addition, larvae in the amino acid and sugar mixture for $24 \mathrm{~h}$ had a significantly larger lophophore surface area and volume (23 and 31\%, respectively), compared to larvae in DOM-depleted seawater. To ensure that the increases in performance found in larvae with access to DOM were not due to a decrease in metabolic activity, the respiration rates for these larvae were compared to those of larvae in DOMdepleted seawater. There were no significant differences between these treatments, indicating that the increases in performance were due to the energy acquired from DOM. These results clearly show that for $B$. neritina, DOM uptake results in increased metamorphic success and in the size of the feeding apparatus following an extended larval swimming duration.

\section{Introduction}

It is well known that aquatic microorganisms and protozoans use naturally occurring dissolved organic matter (DOM) as a source of carbon and nitrogen for growth and reproduction (e.g., Crawford et al. 1974; Williams et al. 1976). First hypothesized in the late 1800s (reviewed by Jørgensen 1976), DOM has long been considered a potential energy source for metazoans as well. The epidermal uptake of free amino acids, fatty acids, and sugars has been demonstrated for numerous invertebrates, and it has been shown that associated bacteria are probably not responsible for the net-uptake 
of DOM (e.g., Jørgensen 1976; Stephens 1988; Manahan 1990). However, what remains a pressing and as yet unanswered question is the extent to which the uptake of DOM actually contributes to the overall growth, reproduction and survival of metazoans.

Marine DOM represents one of the largest carbon reservoirs on Earth (Carlson 2002), with typical bulk concentrations of $50-100 \mu \mathrm{M}$ in surface waters and 35$50 \mu \mathrm{M}$ in deeper waters (Benner 2002). Most of the DOM pool is composed of refractory DOM (i.e., nonbioreactive) (Carlson 2002), while labile (useable) DOM, primarily neutral sugars and amino acids, makes up only about $3-10 \%$ of the total dissolved organic carbon pool (Benner 2003). Despite being such a small fraction, the turnover rate of monosaccharides and free amino acids is rapid, often supporting a large proportion of bacterial growth in both marine and freshwater environments (Kirchman 2003). Unlike freshwater systems, where DOM is introduced by allochthonous sources, the accumulation of DOM in the marine environment comes mostly from autochthonous sources (e.g., Aitkenhead-Peterson et al. 2003). Organic compounds are introduced to the marine environment by phytoplanktonic cell lysis, "sloppy" grazing by zooplankton, and release of fecal pellets by zooplankton (Carlson 2002). Although it has been thought that bacteria are responsible for consuming most naturally occurring DOM (Azam and Hodson 1977), there is significant evidence that metazoans also use these organic compounds (e.g., Stephens 1988; Manahan 1990).

A seminal study conducted by Stephens and Schinske (1961) found via colorimetric observation that animals representing ten phyla removed significant quantities of glycine from solution. Although this uptake occurred using glycine concentrations far exceeding those found naturally (approximately $2 \mathrm{mM}$ ), Stephens (1962) further showed the appearance of radiolabeled glucose within the solitary coral Fungia scutaria in concentrations as low as $5.5 \mu \mathrm{M}$. Following these initial observations, numerous studies have demonstrated the uptake of dissolved organics by invertebrates in both adults (e.g., Ferguson 1982) and larvae (reviewed by Manahan 1990). For example, Jaeckle and Manahan (1989) found larvae of the red abalone Haliotis rufescens could transport basic, neutral, and acidic amino acids, and that this transport could potentially account for 70 and $39 \%$ of the metabolic needs of 2- and 3-day-old larvae, respectively. More recently, it has been demonstrated for larvae of the bryozoan $B$. neritina that the rate of uptake of palmitic acid (PA) was sufficient to account for $21-72 \%$ of the total energetic requirements (Jaeckle 1994).

The ability of invertebrate larvae to utilize DOM could have dramatic effects on their survivability, particularly for non-feeding larvae (e.g., Woollacott et al. 1989; Pechenik and Cerulli 1991; Maldonado and Young 1999). For example, Wendt (1996) found that delaying metamorphosis by $B$. neritina larvae led to a significant decrease in survivability, as judged by a decrease in initiation and completion of metamorphosis. In addition, larvae successfully completing metamorphosis had significantly smaller lophophores (feeding apparatus) in the post-metamorphic juvenile (ancestrula). As lophophore size has been correlated with feeding current velocity (Best and Thorpe 1986), this decrease in size suggests reduced fitness due to decreased feeding rate. Wendt (1998) further demonstrated that the smaller lophophore due to prolonged larval swimming led to a decrease in not only growth, but also reproduction rates in adult colonies. Integumental uptake and utilization of DOM could act as an energy source, offsetting the metabolic costs of prolonged swimming. In turn, this could then lead to an increased chance of survival and enhanced postmetamorphic fitness for individuals experiencing a prolonged larval swimming duration, as well as potentially greater larval dispersal distance and increased gene flow among distant populations.

Previous studies examining DOM uptake have demonstrated integumental transport of DOM in numerous species, but most have not dealt directly with the ecological benefits experienced. Rather, potential benefits have been estimated by comparing metabolic expenditure and the amount of energy gained through rates of DOM uptake (e.g., Jaeckle and Manahan 1989; Shilling and Manahan 1994; Jaeckle 1994; Ben-DavidZaslow and Benayahu 2000). A more direct assessment of the energetic and ecological benefits of DOM transport could be achieved through performance comparisons of individuals in the presence and absence of DOM. Surprisingly, these types of experiments are almost wholly lacking, and we know of only two previous studies that conducted such comparisons. In one study, Shick (1975) found that Aurelia aurita scyphistomae with access to artificial seawater enriched with DOM had a higher rate of adult asexual reproduction, compared to individuals growing in artificial seawater without supplemental DOM. In contrast, Ferguson (1980a) found that after 160 days, adults of the sea star Echinaster sp. reared in DOM-depleted seawater showed no differences in behavior, appearance of the epidermis, and biochemistry and size of body parts, compared to individuals reared in DOM enriched seawater, despite having previously shown this species to take up DOM (Ferguson 1967, 1980b)

Using the bryozoan $B$. neritina as a model system, we sought to determine the realized energetic benefit of DOM uptake by comparing the performance of 
larvae swimming in the presence and absence of DOM. $B$. neritina is ideal for this type of study because: (1) the larvae are non-feeding; the only energy available is that provided by the maternal zooid or what can be gained through DOM uptake, (2) the organism has a short larval swimming duration; larvae are competent to metamorphose within $1 \mathrm{~h}$ after release, but initiation can be delayed through the use of bright light (Wendt 1996) or curtailed with excess $\mathrm{KCl}$ (Wendt and Woollacott 1995), (3) an extended larval swimming period causes a significant reduction in the ability to initiate and complete metamorphosis, smaller sized individuals after metamorphosis, and decreased postmetamorphic growth and reproduction (Wendt 1996, 1998), (4) previous work has demonstrated the energetic requirements for larval swimming and metamorphosis; following a $20 \mathrm{~h}$ swimming duration, larvae utilize 7 and $28 \%$ of their energy reserves for swimming and metamorphosis, respectively (Wendt 2000), and (5) the larvae take up DOM (Jaeckle 1994). A necessary initial step in conducting these performance comparisons was to reduce naturally occurring DOM in seawater, which was accomplished by ultraviolet (UV) irradiation (Beattie et al. 1961; Armstrong et al. 1966; Armstrong and Tibbitts 1968). Following this, known types and quantities of DOM were added to treated water, thus allowing for comparisons of B. neritina larvae swimming in DOM-depleted and DOM-enriched conditions. We then compared the performance of individuals in DOM-reduced and DOM-enriched conditions by assessing: (1) the ability of larvae to initiate metamorphosis, (2) the ability of larvae to complete metamorphosis, and (3) the size of ancestrular lophophores after metamorphosis. We hypothesized that larvae swimming in the DOM-enriched treatments should experience increased performance, compared to larvae swimming in the DOM-depleted treatment.

\section{Materials and methods}

Preparation of glassware

All glassware used was initially treated with $10 \% \mathrm{HCl}$ for approximately $24 \mathrm{~h}$, then rinsed with copious amounts of distilled water. Prior to each experiment, with the exception of the fused-quartz test tubes used in the DOM-depletion experiment, all glassware was covered with aluminum foil and subjected to $500^{\circ} \mathrm{C}$ for 2-3 h to combust residual DOM. To prevent contamination, glassware remained covered until used. Herein, glassware subjected to this high temperature sterilization is designated as "treated".
Larval culture

Brine shrimp, Artemia sp., larvae were hatched from cysts purchased locally (Aquatic Adventures, San Luis Obispo, California, USA) from August to December 2003. Following the manufacturer's instructions, $1 \mathrm{~g}$ of cysts was added to 11 of $0.2 \mu \mathrm{m}$-filtered seawater (FSW) (35 ppt), and continuously aerated at $15^{\circ} \mathrm{C}$ in a constant temperature incubator. Hatching generally occurred within 24-36 h, and unfed larvae were maintained in aerated FSW prior to use. Approximately 48$\mathrm{h}$ old larvae were used.

Adult sea urchins, Strongylocentrotus purpuratus (Stimpson 1857), were collected from floating docks in Morro Bay, CA, USA, in February 2004, and maintained in a 125-gallon aquarium, equipped with an Eco-wheel $^{\odot}$ filtration assembly (Aquatic Engineers, Camby, IN, USA), until needed for spawning. Following Strathman (1987), spawning was induced by injecting $0.5 \mathrm{M} \mathrm{KCl}$ into the coelomic cavity of multiple females and males. Pooled eggs were washed 2-3 times with FSW and mixed with $1 \mathrm{ml}$ of diluted sperm. After $30 \mathrm{~min}$, fertilized eggs were transferred to finger bowls containing $11 \mathrm{FSW}\left(35 \mathrm{ppt}\right.$ ) and kept at $12^{\circ} \mathrm{C}$ with $\mathrm{FSW}$ changes performed daily. Three to 4-day old prism stage larvae were used for all trials.

Larvae of the red abalone Haliotis rufescens (Swainson 1822) were procured from a commercial abalone hatchery (The Abalone Farm, Inc., Cayucos, CA, USA) from February to March 2004. Developing embryos and larvae were maintained in 50-gallon containers with a constant influx and efflux of filtered natural seawater $(<5 \mu \mathrm{m}$ filtration), yielding a complete water change 1-2 times daily. Four- to 5-day old veliger larvae were collected from the hatchery and used immediately. The experiments were conducted at a temperature similar to temperatures used for fertilization and development $\left(\approx 12^{\circ} \mathrm{C}\right)$.

Adult colonies of $B$. neritina (Linnaeus 1758) were collected from floating docks at Duke University Marine Laboratory in Beaufort, North Carolina from June to September 2004. Colonies were maintained in the dark in 5-gallon aerated containers in a constant temperature incubator $\left(25^{\circ} \mathrm{C}\right)$. Water changes were performed daily. As larvae released from colonies maintained in the laboratory for $>7$ days experience reduced rates of metamorphic initiation and completion (personal observation, Wendt and Woollacott 1995), only larvae from colonies maintained for $<6$ days were used. To facilitate larval release and collection each morning, 10-12 adult colonies were removed from the dark, placed in glass bowls with 11 of $5 \mu \mathrm{m}$ FSW (35 ppt), and exposed to fluorescent light 
(Wendt 1996). Larval release usually commenced within $15 \mathrm{~min}$ of illumination, and lasted for approximately $1 \mathrm{~h}$. Larvae were used immediately following collection.

\section{UV-oxidation of DOM}

Labile DOM was reduced in seawater through the use of a photo-oxidation apparatus (Ace Glass \#7900), as judged by total organic carbon (TOC) measurement. Seawater (34-36 ppt) was collected at the Center for Coastal Marine Sciences (Avila Beach, California, USA) in August 2003 and passed through a $0.2-\mu \mathrm{m}$ filter. Approximately $120 \mathrm{ml}$ of FSW were then decanted into $10 \mathrm{UV}$-transparent, fused-quartz test tubes. Twenty-ml samples from each test tube were taken prior to UV treatment for the initial TOC value. The test tubes were then affixed within a cylindrical lamp housing, centered about a 1,200 W UV lamp (222-366 nm), and buffered from the lamp's operating temperature $\left(800^{\circ} \mathrm{C}\right)$ with a base-mounted cooling fan. Twenty milliliters samples from each test tube were taken following $12 \mathrm{~h}$ of continuous UV irradiation, and again after another $6 \mathrm{~h}$ of irradiation. All samples taken were decanted into "treated" 40-ml glass vials and immediately frozen. Sampled water was analyzed for TOC using a Shimadzu TOC-V analyzer. The analyzer was calibrated using a blank of UV-oxidized Nanopure ${ }^{\odot}$ water and potassium hydrogen pthalate (KHP) standards of 25, 50, 75, and $100 \mu \mathrm{M} \mathbf{C}$.

Comparison of metabolic rates in UV-treated and untreated water

To ensure that UV-oxidation of seawater did not have an adverse effect on larvae (i.e., by creating a toxic environment through the release of heavy metals, free radicals, etc.), the respiration rates of larvae swimming in treated and untreated water were compared. Larvae representing four different phyla (Arthropoda, Echinodermata, Mollusca, and Bryozoa) were used as it was expected that different phyla might have different environmental sensitivities. Comparisons of metabolic rates of four species of invertebrate larvae swimming in treated and untreated water demonstrated UV-irradiated seawater had no deleterious effects on larvae. Larvae were initially collected and transferred to $500 \mathrm{ml}$ of either FSW or UV-irradiated FSW (UVSW). Larvae were then transferred in $1.2 \mathrm{ml}$ of either treatment to a 5-ml glass syringe (Perfektum ${ }^{\circledR}$ model \#5015) at densities of 46-80 individuals for Artemia sp., 255-916 individuals for $S$. purpuratus, 44-182 individuals for
H. rufescens, and 16-181 individuals for B. neritina. There were no significant differences in the concentration of individuals used in each treatment for each species. To avoid the problems associated with oxygen determination using a polarographic oxygen sensor (Marsh and Manahan 1999), oxygen concentration was measured using the technique of fluorescence quenching (Klimant et al. 1995; Gatti et al. 2002). Oxygen depletion was continuously measured with a titaniumtipped fiber optic probe (Instech model \#125/FO) connected to an oxygen meter (Ocean Optics model \#210). The probe was inserted through the syringe tip, with a custom-built syringe tip adapter used to ensure an airtight seal. This assembly was then immersed in 11 of temperature acclimated $\left(15^{\circ} \mathrm{C}\right.$ for Artemia sp., $12^{\circ} \mathrm{C}$ for $S$. purpuratus and $H$. rufescens, and $25^{\circ} \mathrm{C}$ for $B$. neritina) de-ionized water to prevent any fluctuations in temperature. The oxygen monitor was calibrated using a zero oxygen solution and air equilibrated seawater, as per the manufacturer's instructions. The zero oxygen solution was obtained by adding sodium dithionite to temperature acclimated seawater. Levels of oxygen for the air-equilibrated water for each experiment were calculated using the barometric pressure, vapor pressure, and standard values of oxygen solubility for specific temperatures and salinity (Weast and Astle 1980). The experiments ran for $15 \mathrm{~min}, 4 \mathrm{~h}, 40$ and $15 \mathrm{~min}$ for Artemia sp., S. purpuratus, H. rufescens, and B. neritina, respectively, until initial oxygen concentration was depleted by $\approx 10 \%$. Upon completion of the experiment, larvae were rinsed from the syringe with FSW and counted. Controls correcting for the background rate of oxygen consumption in each condition were run immediately following the larval trials. The rate of oxygen consumption per individual was calculated by first correcting for background respiration, then dividing the regression coefficient of oxygen decrease per second by the number of individuals, multiplying by the volume of water, and then multiplying by 3,600 to yield moles $\mathrm{O}_{2}$ consumed $\mathrm{h}^{-1}$ ind $^{-1}$.

\section{Performance comparisons}

To determine the extent to which DOM could serve as a nutritional source for $B$. neritina larvae, performance comparisons were made between larvae swimming in DOM-depleted and DOM-enriched seawater. The experimental treatments used were FSW, UV-irradiated seawater (UVSW), UVSW enriched with $1 \mu \mathrm{M}$ each of alanine, aspartic acid, glucose and glycine (Mixture), and UVSW enriched with $1 \mu \mathrm{M}$ of Palmitic acid. Alanine, aspartic acid, glucose, glycine and PA were selected for DOM enrichment based on previous 
studies that found each of these compounds to be readily transported by various animals (e.g., Stephens and Schinske 1961; Stephens 1962; Shick 1975; Ferguson 1980b; Manahan et al. 1982; Manahan 1983; Jaeckle and Manahan 1989; Jaeckle 1994, 1995). The concentrations utilized were based on concentrations naturally occurring in surface water (Benner 2003). Larvae were collected and transferred to $250 \mathrm{ml}$ of UVSW. Approximately 300 larvae were then transferred to each experimental treatment in the smallest volume possible (always $<1 \mathrm{ml}$ of seawater). As PA has a relatively low solubility in water, it was necessary to first dissolve it in ethanol (Jaeckle 1994) and an ethanol control condition consisting of UVSW enriched with $0.01 \%$ ethanol was used. To address any potential adverse or beneficial effects of the ethanol, comparisons between that experimental condition and the UVSW experimental condition were performed. There were no significant differences found between these conditions for the initiation of metamorphosis [ $\left(2 \times \text { arcsine } Y^{1 / 2}\right)^{2}$ transformed] [two-way analysis of variance (ANOVA): $d f=1$, adj $\mathrm{SS}=0.102, F=0.020$, $P=0.884, n=7$ trials], completion of metamorphosis (Scheirer-Ray-Hare: $d f=1$, adj SS $=44, \mathrm{MS}_{\text {total }}=198$, $P=0.637, n=7$ trials), lophophore height (three-way ANOVA: $d f=1$, adj SS $=3933, F=2.270, P=0.133$, $n=6$ trials), lophophore volume ( $Y^{1 / 2}$ transformed) (three-way ANOVA: $d f=1$, adj $\mathrm{SS}=0.0009, F=1.80$, $P=0.181, n=6$ trials), and lophophore surface area (three-way ANOVA: $d f=1$, adj $\mathrm{SS}=0.0091, F=2.10$, $P=0.149, n=6$ trials). Thus, the ethanol used did not, in itself, provide any detectable energetic benefit or harm to the larvae.

Bugula neritina larvae swimming in each treatment were placed on a 0.5 -in. thick, clear acrylic table and illuminated from below using four 20-W, 24-in. GE Cool White ${ }^{\mathrm{TM}}$ fluorescent bulbs. Two fluorescent bulbs were also placed at each end of the table ensuring ample surrounding illumination. This arrangement had no effect on the temperature of the water within the finger bowls over the duration of the experiment $\left(25^{\circ} \mathrm{C}\right)$. Swimming larvae were sampled at $1,6,12$, and $24 \mathrm{~h}$ after their release. Approximately 10-20 larvae were removed from their treatment and introduced to covered Stender dishes containing $10 \mathrm{ml}$ UVSW with $10 \mathrm{mM}$ excess $\mathrm{KCl}$, inducing metamorphosis (Wendt and Woollacott 1995). Following a 4-h settlement period, attached individuals (i.e., initiated metamorphosis) were counted and re-introduced to their original swimming treatment. Larvae were assayed for successful metamorphic completion approximately $48 \mathrm{~h}$ after the initiation of metamorphosis, except for individuals developing from larvae swimming for $24 \mathrm{~h}$.
These individuals were given approximately $72 \mathrm{~h}$ to complete metamorphosis, as the average time to complete metamorphosis increases as a function of larval swimming duration (Wendt 1996). For those larvae that successfully completed metamorphosis, the size of the lophophore base diameter, crown diameter, and tentacle length were measured using a Wild M5 $(50 \times)$ dissecting microscope. These measurements were then used to calculate the height, volume, and surface area of the lophophore (Wendt 1996). Ancestrulae were exposed to a solution of $7.5 \% \mathrm{MgCl}_{2}$ UVSW to prevent contraction of the lophophore retractor muscle during measurements.

\section{Effect of swimming condition on metabolic rate}

To determine if any performance differences found among the treatments were due to a change in larval metabolic activity, experiments measuring oxygen consumption were conducted on B. neritina larvae swimming in the UVSW and Mixture treatments. Oxygen consumption rates were determined as previously described. UVSW and Mixture were used based on the results showing that the greatest performance discrepancy existed between these two treatments.

\section{Statistical analysis}

The TOC data were transformed with a fourth root transformation to induce a normal distribution and equal variance. Respiration data for each of the four species tested were found to have equal variance, while the Artemia sp. and B. neritina data were square root transformed for normal distributions. Differences in TOC among sampling times, as well as differences in respiration rates between treated and untreated FSW for each species, were analyzed with a one-way ANOVA. Significant results were further analyzed using Fisher's PLSD post hoc analysis. Transformed data were back-transformed for presentation in figures and text.

All data on initiation and completion of metamorphosis were initially analyzed for normality and equality of variance. The percent metamorphic initiation and completion data failed to meet these requirements and were transformed using the transformation $\left[Y^{\prime}=2 \times \text { arcsine }\left(Y^{1 / 2}\right)\right]^{2}$, a derivative of a common transformation for percentages (Neter et al. 1985). The metamorphic initiation data continued to fail these requirements and were back transformed and analyzed with the Scheirer-Ray-Hare non-parametric analyses in lieu of a two-way ANOVA (Sokal and Rohlf 1995). Significant differences found were further 
analyzed with the Mann-Whitney non-parametric analysis. The metamorphic completion data were analyzed by a two-way ANOVA, with swimming duration and condition as factors. Significant differences found were further analyzed with Fisher's PLSD post hoc analysis.

All lophophore parameter data met the assumptions of normality and equal variance, and were then analyzed using a three-way ANOVA, with swimming duration and DOM treatment as fixed factors and release date as a random factor. Significant differences found among sampling times were further analyzed using Fisher's PLSD post hoc analysis. As DOM treatment was not expected to have a significant effect early in the experiment, and that any effect would most likely be manifested only after a substantial decrease in endogenous reserves, significant differences among DOM treatments were further investigated with Tukey's pair-wise comparisons post hoc analysis within the $24 \mathrm{~h}$ sampling time.

The oxygen consumption data for larvae swimming in the UVSW and Mixture treatments were found to be normally distributed with equal variance. These data were analyzed with a one-way ANOVA, with swimming treatment as the factor.

All transformed data were back transformed for presentation in figures and text. All data are presented as means \pm the standard error (SE).

\section{Results}

\section{UV-oxidation of DOM}

Initial TOC values were found to be $184.8 \pm 9.7 \mu \mathrm{M}$ $(n=10)$. UV irradiation significantly reduced TOC by $\approx 90 \%$ of its initial value, to an average value of $22 \pm 1.5 \mu \mathrm{M}$ of organic carbon (ANOVA: $d f=2$, $n=10$, adj SS $=15.38, F=298.9, P<0.0001)$. TOC levels for 12 and $18 \mathrm{~h}$ irradiation times were $23.3 \pm 2.8$ and $21.8 \pm 1.5 \mu \mathrm{M}$, respectively, and were not significantly different (Fisher's PLSD: $P=0.831$ ).
Comparison of metabolic rates in UV-treated and untreated water

Oxygen concentration was continuously monitored and found to decrease at a constant rate over time. For each species, metabolic rates were not significantly different between treatments (Table 1 ). In the B. neritina experiment, a small number of larvae initiated metamorphosis during the respiration trial. There were no significant differences between the two treatments in the percentage of larval attachment at the completion of each respiration trial (Kruskal-Wallis: $H=2.37, d f=1, P=0.124$ ).

\section{Initiation of metamorphosis}

Overall, larval swimming duration significantly affected the ability to initiate metamorphosis for $B$. neritina (Table 2). Metamorphic initiation decreased significantly over the first $12 \mathrm{~h}$ of larval swimming, however, there were no additional significant changes following $12 \mathrm{~h}$ of continuous swimming. On average, more than one third of larvae lost the ability to initiate metamorphosis after $24 \mathrm{~h}$ of larval swimming, compared to larvae that swam for only $1 \mathrm{~h}$ (Table 3 ). The availability of DOM did not affect the ability to initiate metamorphosis during an extended larval swimming period, as there were no significant differences in the percentage of individuals initiating metamorphosis among DOM treatments (Table 2).

\section{Completion of metamorphosis}

The percentage of $B$. neritina larvae completing metamorphosis was significantly affected by larval swimming duration (Table 2). Overall, the percentage of individuals completing metamorphosis was 59.4\% lower for individuals that swam for $24 \mathrm{~h}$, as compared to those that swam for $1 \mathrm{~h}$. Significant differences existed among all sampling times (Fig. 1). The presence of DOM also had a significant effect on the ability to complete metamorphosis (Table 2; Fig. 2). On average, larvae swimming for $24 \mathrm{~h}$ in the FSW and UVSW treatments had a reduction in metamorphic completion
Table 1 Metabolic rates of four species of marine invertebrate larvae in two experimental treatments

Number of trials indicated in parenthesis following rates

\begin{tabular}{|c|c|c|c|c|c|c|}
\hline \multirow[t]{2}{*}{ Species } & \multirow[t]{2}{*}{$\begin{array}{l}\text { Temp } \\
\left({ }^{\circ} \mathrm{C}\right)\end{array}$} & \multicolumn{2}{|c|}{$\begin{array}{l}\text { Metabolic rate } \\
\left(\text { pmol O}_{2} \text { ind }^{-1} h^{-1}\right)\end{array}$} & \multirow[t]{2}{*}{ Adj. SS } & \multirow[t]{2}{*}{$F$ test } & \multirow[t]{2}{*}{$P$ value } \\
\hline & & FSW & UVSW & & & \\
\hline Artemia sp. & 15 & $422 \pm 38(22)$ & $397 \pm 33(22)$ & $3.20 \times 10^{-8}$ & 0.18 & 0.670 \\
\hline S. purpuratus & 12 & $6.41 \pm 0.8(12)$ & $7.43 \pm 2.1(10)$ & $3.60 \times 10^{-12}$ & 0.32 & 0.578 \\
\hline H. rufescens & 12 & $156 \pm 21$ & $176 \pm 19(13)$ & $2.60 \times 10^{-11}$ & 0.50 & 0.487 \\
\hline B. neritina & 25 & $651 \pm 118(19)$ & $600 \pm 84(27)$ & $1.25 \times 10^{-6}$ & 0.15 & 0.701 \\
\hline
\end{tabular}


Table 2 Bugula neritina. Effect of swimming duration and DOM availability on initiation and completion of metamorphosis ( $n=7$ trials $)$ and lophophore size ( $n=6$ trials)

\begin{tabular}{llllrl}
\hline Measurement & Factor & $d f$ & Adj. SS & $F$ test & $P$ value \\
\hline Metamorphic initiation & *Swimming duration & 3 & 35,406 & & $<0.001$ \\
& DOM treatment & 3 & 4,152 & & 0.139 \\
& Interaction & 9 & 3,119 & & 0.903 \\
Metamorphic completion & *Swimming duration & 3 & 663.912 & 53.05 & $<0.001$ \\
& *DOM treatment & 3 & 34.751 & 2.78 & 0.046 \\
& Interaction & 9 & 25.805 & 0.69 & 0.718 \\
Lophophore height & *Swimming duration & 3 & 1.054 & 201.82 & $<0.001$ \\
& DOM treatment & 3 & 0.012 & 2.26 & 0.080 \\
& *Interaction & 9 & 0.045 & 2.87 & 0.003 \\
Lophophore volume & *Release date & 5 & 0.081 & 9.35 & $<0.001$ \\
& *Swimming duration & 3 & 0.037 & 229.58 & $<0.001$ \\
& *DOM treatment & 3 & 0.001 & 5.54 & 0.001 \\
& *Interaction & 9 & 0.001 & 2.26 & 0.017 \\
Lophophore surface area & *Release date & 5 & 0.001 & 10.78 & $<0.001$ \\
& *Swimming duration & 3 & 3.448 & 255.85 & $<0.001$ \\
& *DOM treatment & 3 & 0.074 & 5.52 & 0.001 \\
& *Interaction & 9 & 0.102 & 2.51 & 0.008 \\
& *Release date & 5 & 0.219 & 9.75 & $<0.001$ \\
\hline
\end{tabular}

Table 3 Bugula neritina. Effect of four larval swimming durations on initiation of metamorphosis

\begin{tabular}{lllll}
\hline $\begin{array}{l}\text { Swimming } \\
\text { duration }(\mathrm{h})\end{array}$ & $n$ & $\begin{array}{l}\text { \% Mean } \\
\text { settlement }\end{array}$ & $\begin{array}{l}\text { Standard } \\
\text { error }\end{array}$ & $P$ value \\
\hline 1 & 586 & 98.0 & 0.8 & \\
6 & 436 & 93.2 & 2.4 & 0.118 \\
12 & 446 & 81.5 & 2.8 & \\
24 & 667 & 64.8 & 5.8 & \\
\hline
\end{tabular}

Times not enclosed by bars are significantly different (MannWhitney: $P<0.029 ; n=$ total number of larvae sampled in seven trials)

of $\approx 71 \%$, compared to larvae swimming for only $1 \mathrm{~h}$ (Fig. 2a). In contrast, larvae swimming for $24 \mathrm{~h}$ in the Mixture and PA treatments experienced a reduction in metamorphic completion of only $49 \%$, compared to larvae swimming for only $1 \mathrm{~h}$ (Fig. 2b).

\section{Lophophore size}

Increased swimming duration significantly affected the size of the ancestrular lophophore in each of the calculated parameters (Table 2). Larvae swimming for $24 \mathrm{~h}$ experienced a mean reduction in lophophore height, volume, and surface area of $30.5,61.1$, and $49.5 \%$, respectively, compared to larvae that swam for only $1 \mathrm{~h}$. All sampling times within each parameter were significantly different from each other (Fisher's PLSD: $P<0.001$ ). The DOM treatment also had a significant effect on lophophore size, as judged by lophophore volume and surface area (Table 2). Tukey's pair-wise comparisons within the 24-h sampling period found no significant differences among the FSW, Mixture, and PA conditions for these

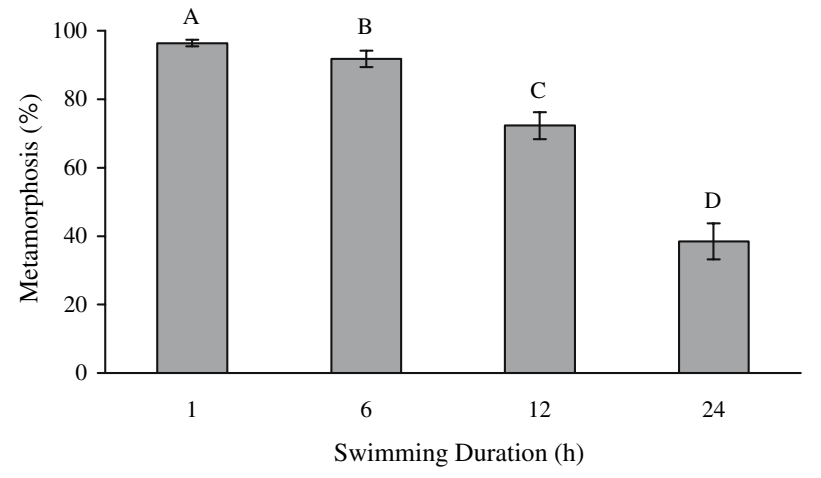

Fig. 1 Bugula neritina. The effect of larval swimming duration on successful completion of metamorphosis. Different letters above error bars denote significant differences among sampling times (Fisher's PLSD: 1 and $6 \mathrm{~h}-P=0.044$; all other pairs $-P<0.0001$; bars $=1 \mathrm{SE}$ )

parameters. However, significant differences were found between the UVSW and Mixture treatments for volume $(P=0.002)$ and surface area $(P=0.001)$ (Fig. 3$)$. On average, larvae swimming in the Mixture treatment had a $31 \%$ larger lophophore volume and a 23\% larger lophophore surface area, compared to larvae swimming for $24 \mathrm{~h}$ in the UVSW condition. There were no significant differences in these parameters between the UVSW and Mixture treatments within the 1-h sampling period (Fig. 3). Although not significant, the lophophore height data trended similarly to the volume and surface area data.

\section{Effect of DOM treatment on metabolic rate}

Oxygen concentration was continuously monitored and found to decrease at a constant rate over time. The 

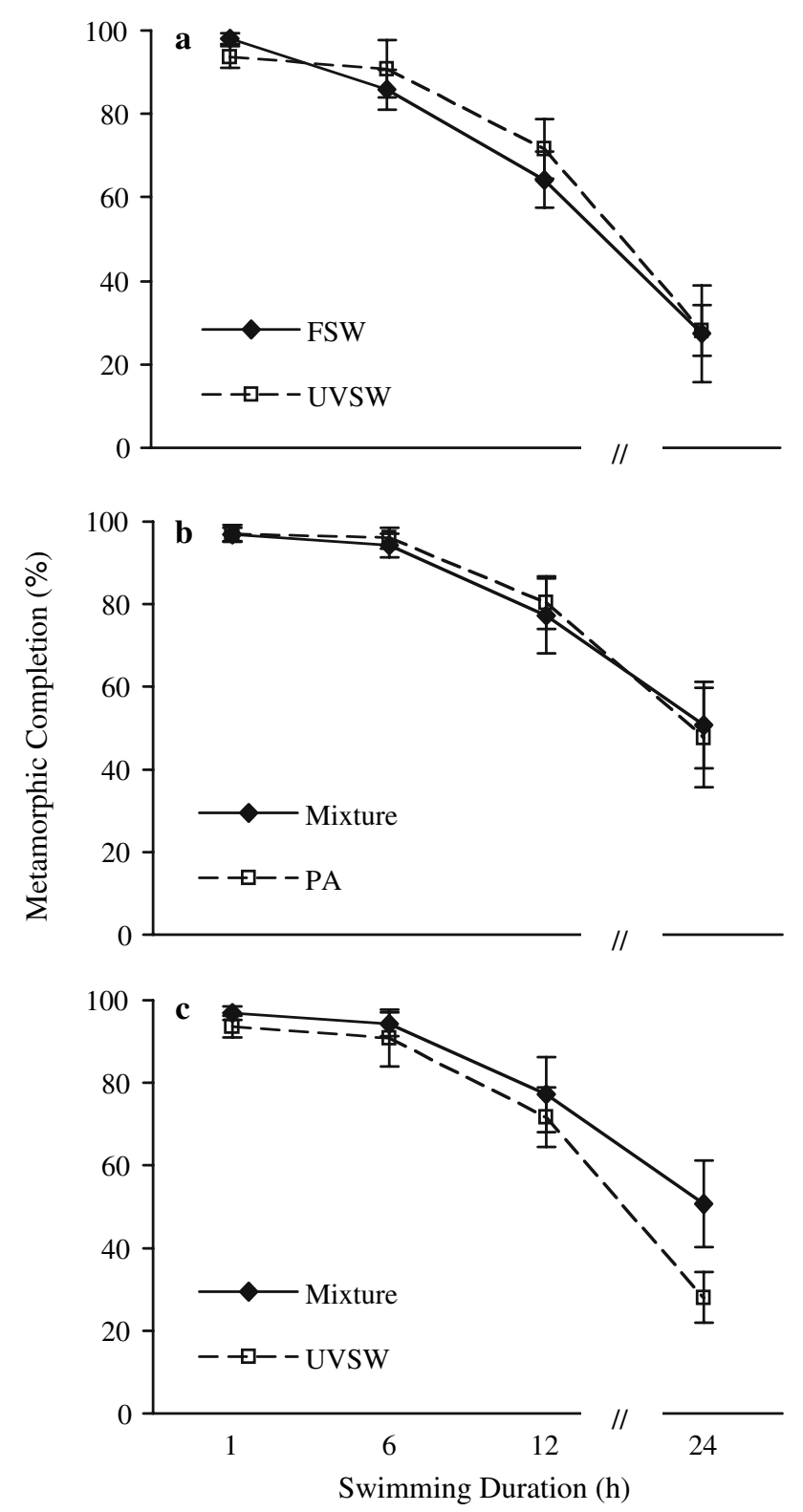

Fig. 2 Bugula neritina. Average percentage of larvae completing metamorphosis as a function of swimming duration and DOM treatment $(n=7$ trials, bars $=1 \mathrm{SE})$. No significant difference in the ability to successfully complete metamorphosis was found between the FSW and UVSW treatments $(\mathbf{a})(P=0.610)$, nor between the enriched Mixture and PA treatments $(\mathbf{b})(P=0.753)$. A significant difference was found between the Mixture and UVSW treatments $(\mathbf{c})(P=0.046)$, and all other pairs (PA and UVSW $P=0.028$, PA and FSW $P=0.009$, and Mixture and FSW $P=0.015)$. Missing bars denote error too small to be visualized

average metabolic rate for $B$. neritina larvae swimming in the UVSW treatment was $612 \pm 76 \mathrm{pmol}$ $\mathrm{O}_{2}$ ind $^{-1} \mathrm{~h}^{-1}$ ( $n=13$ trials), while the metabolic rate for larvae swimming in the Mixture treatment was $609 \pm 70 \mathrm{pmol} \mathrm{O}_{2}$ ind $^{-1} \mathrm{~h}^{-1} \quad(n=15$ trials $) \quad\left(25^{\circ} \mathrm{C}\right)$. There was no significant difference in larval metabolic rate between these treatments (ANOVA: $d f=1$,
$\left.\mathrm{SS}=4.46 \times 10^{-23}, F=0.001, P=0.980\right)$. In addition, there was no significant difference between the two treatments in the percentage of larval attachment at the completion of each respiration trial (Kruskal-Wallis: $H=1.55, d f=1, P=0.214)$.

\section{Discussion and conclusions}

It is thought that the ability of invertebrate larvae to utilize DOM could have dramatic effects on the survivability of the larvae, although this has previously not been directly demonstrated. The majority of studies examining the nutritional role of DOM have focused primarily on indirect estimations of benefit attained by calculations based on metabolic activity and uptake rate (e.g., Jaeckle and Manahan 1989; Shilling and Manahan 1994; Jaeckle 1994; Ben-David-Zaslow and Benayahu 2000). Direct comparisons determining the actual benefit of DOM transport to growth, survivability and reproduction of organisms are almost wholly lacking from the literature and have yielded contradictory results (e.g., Shick 1975; Ferguson 1980a). Our study demonstrates conclusively energetic and ecological benefits of DOM transport to the marine bryozoan Bugula neritina. Our data show that a mixture of DOM at realistic concentrations (Benner 2003) had the ability to offset the deleterious effects associated with an increased larval swimming phase in (1) the ability to complete metamorphosis, and (2) size of the lophophore as determined by lophophore volume and surface area.

Our results clearly show that UV-treated water does not have an adverse effect on larvae (Table 1). Previous work has demonstrated that labile DOM (i.e., carbohydrates, amino acids, and lipids) account for approximately $3-10 \%$ of the total DOC found in seawater (Benner 2003), and that those labile compounds are completely oxidized with UV irradiation (Armstrong 1966). Specifically, Armstrong (1966) showed that adenine, phenylalanine, glucose, and PA at concentrations of $1-2 \mathrm{mg} / \mathrm{l}$ (three orders of magnitude higher than found in natural seawater) were completely oxidized within $2-3$ h irradiation period. However, there have been no previous studies that have examined the effect UV-oxidized seawater might have on larvae. Here, our data show no difference in the metabolic rates of larvae swimming in untreated and treated water, indicating that there were no adverse short-term effects associated with using ultraviolet light to remove DOM from seawater. Any differences found between DOM conditions could thus be attributed to the presence or absence of DOM, rather than to potentially harmful by-products associated with UV-oxidation. 

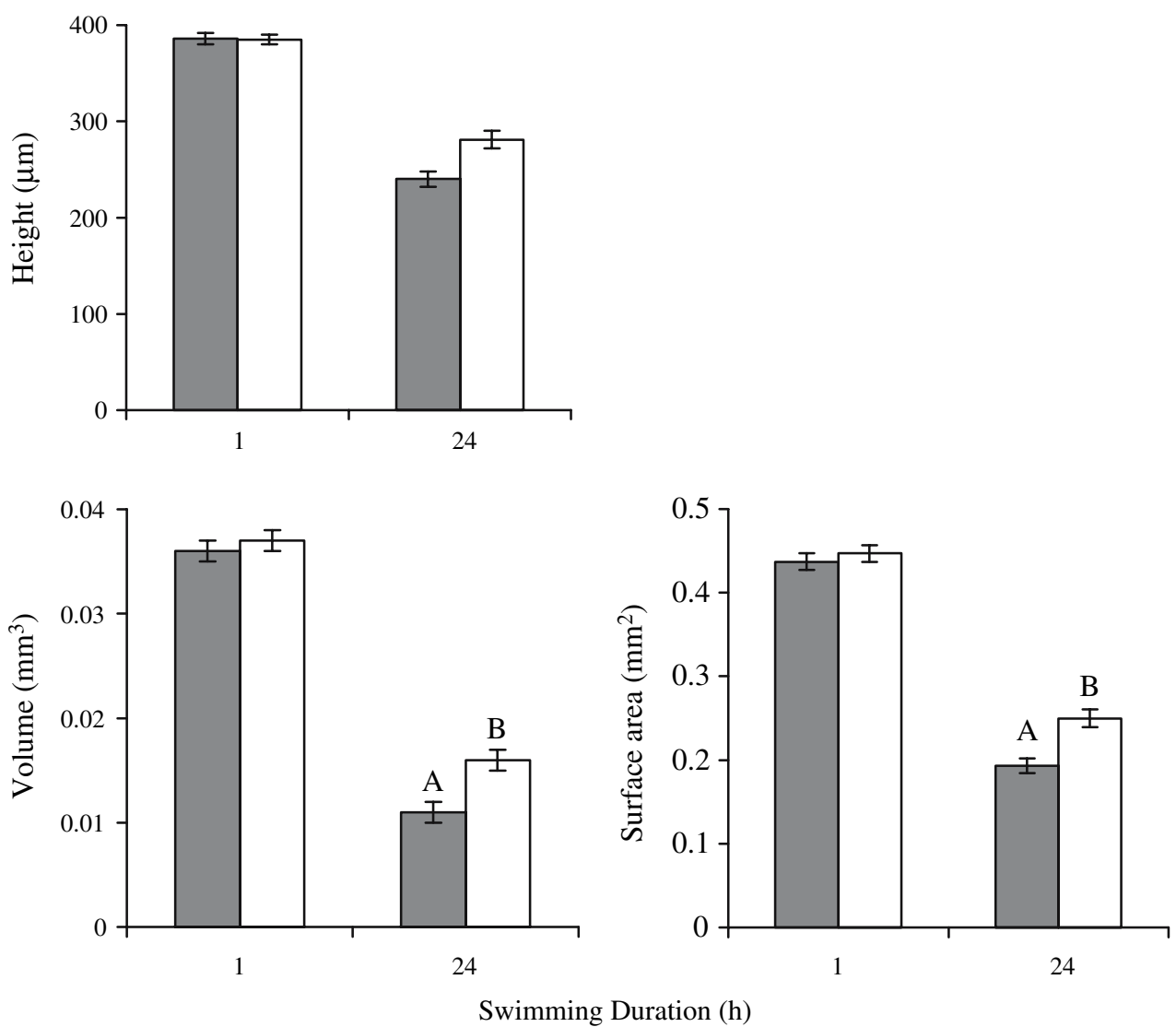

Fig. 3 Bugula neritina. Average lophophore height, volume, and surface area for two sampling times in UVSW (shaded bars) and Mixture experimental treatments. Different letters above error bars (1 SE) indicate significant differences between treatments

The length of the larval swimming duration had a significant effect on metamorphic initiation, yet DOM treatment did not have a significant effect (Table 2). This is consistent with Wendt (1996), who argued that the initiation of metamorphosis for this organism might not depend directly on energetic reserves. Instead, he suggested that the loss of the ability to initiate metamorphosis in $B$. neritina might result from non-energetic mechanisms such as receptor degradation, which prevents larvae from responding to environmental cues that normally elicit metamorphosis. Our data are consistent with this interpretation. If initiation of metamorphosis was exclusively controlled by depletion of energetic reserves, it would be expected that as swimming duration increased, larvae would continuously experience reduced metamorphic initiation. Instead, we found that there was no significant reduction in initiation between larvae swimming for 12 and $24 \mathrm{~h}$ (Table 3). Moreover, initiation of metamorphosis was not affected by DOM condition in our experiments, further suggesting that the ability to initiate metamor- after $24 \mathrm{~h}$ (Tukey's pair-wise comparison: $P \leq 0.010)$. No significant differences were found after $1 \mathrm{~h}$ (Tukey's pair-wise comparison: $P>0.760$ )

phosis is not exclusively controlled by depletion of energetic reserves.

Overall, swimming duration was found to significantly affect completion of metamorphosis (Table 2). Similar to Wendt (1996), we found that successful metamorphic completion was directly correlated with larval swimming duration. Because the larva is non-feeding, continuous swimming results in continuous depletion of endogenous reserves. Our data show that only a portion of larvae initiating metamorphosis actually complete it. When energetic reserves are depleted past some critical level, the larvae are no longer able to complete metamorphosis. For example, after $24 \mathrm{~h}$ of continuous swimming regardless of treatment, on average $65 \%$ of larvae initiate metamorphosis (Table 3 ), but only $40 \%$ complete it (Fig. 2). That completion of metamorphosis depends directly on energetic reserves is further demonstrated in that availability of DOM was sufficient to offset the reduction in metamorphic completion associated with a prolonged larval swimming phase (Fig. 2). Larvae that were able to supplement their metabolic 
activity with energy acquired from DOM transport were able to significantly increase their ability to complete metamorphosis. These data clearly demonstrate a direct ecological benefit of DOM transport.

The size of the lophophore, a fitness related character, was found to decrease significantly as swimming duration increased (Table 2; Fig. 3). As with Wendt (1996), these results suggest that the size of the lophophore depends in part on the amount of energetic reserves, thus illustrating detrimental effects associated with a prolonged larval swimming period. Because of the reduction in lophophore size, larvae with a protracted swimming period would be expected to have reduced feeding rates (Best and Thorpe 1986). A reduction in lophophore size, and presumably feeding rates, also culminates in a reduced growth rate, later onset of reproduction, and a reduced reproductive output (Wendt 1998). DOM condition was shown to significantly offset the decrease in lophophore size, demonstrating an additional benefit of DOM transport. Additionally, lophophore size was significantly affected by the date of larval release (Table 2). These data might be indicative of varying environmental conditions (i.e., water quality and food availability) throughout the duration of the study. To ensure that the benefits observed in metamorphic completion and lophophore size experienced by larvae swimming in the Mixture treatment were not due to differences in metabolic activity (i.e., reduced energy expenditure), the metabolic rates of larvae swimming in this treatment were compared to the rates of those swimming in the UVSW treatment. These results demonstrate that the introduction of dissolved organics did not have a significant effect on larval metabolic activity. As such, we are confident that the increase in metamorphic completion and lophophore size found in larvae swimming in the presence of DOM is due to the energy acquired through DOM transport, rather than a shift in basal metabolic activity.

Interestingly, there were no significant differences found between the FSW and UVSW conditions for both completion of metamorphosis (Fig. 2) and lophophore size (Tukey's pair-wise comparison: volume, $P=0.526$; surface area, $P=0.629$ ). It might have been expected that larvae swimming in the FSW condition had access to natural levels of DOM for use as a nutritional source and should have experienced increases in performance. One possible explanation is that the levels of labile dissolved organics used for these experiments $(1 \mu \mathrm{M})$ are not indicative of normal conditions; although FSW contains significant amounts of DOM, it is composed primarily of refractory compounds not available for use as an energy source. Instead, these labile DOM levels might only be achieved during distinct events or in certain habitats, such as during an algal bloom or in areas near the benthic environment where one might find increased productivity. Hence, the larvae swimming in the FSW condition were swimming in an environment essentially devoid of labile DOM, as compared to the DOM-enriched conditions, and their reduced metamorphic completion and lophophore size reflected this discrepancy.

Our study showed that for Bugula neritina, DOM availability during an extended larval swimming period and metamorphosis had significant effects on both metamorphic success and post-metamorphic size, demonstrating ecological benefits of DOM transport. Larvae experiencing a prolonged swimming duration in the presence of DOM potentially have a $20 \%$ greater chance of completing metamorphosis, hence a $20 \%$ greater rate of survival, compared to larvae swimming and metamorphosing in the absence of DOM. In addition to an increased survival rate, these larvae were also shown to have a significantly increased lophophore size, potentially resulting in an increased feeding rate (Best and Thorpe 1986). This increased feeding rate may then culminate in an increase in both growth and reproduction, which have previously been shown to be reduced as a result of protracted larval swimming in $B$. neritina (Wendt 1998). Because these larvae are non-feeding, have been shown to transport DOM, and have measurable deleterious effects associated with a prolonged larval swimming duration, this study also demonstrates that $B$. neritina is a model system for determining the realized benefit of DOM uptake by marine invertebrates. To determine the generality of our result with $B$. neritina, future studies investigating the energetic and ecological importance of DOM transport to other species of marine invertebrates are needed.

Acknowledgments We thank George Trevelyan (The Abalone Farm, Cayucos, CA) for graciously providing abalone larvae and technical assistance. Craig Carlson (UCSB) conducted the TOC analysis and provided suggestions improving the study. We also thank Dan Rittschof (Duke University Marine Lab) for allowing portions of this study to be conducted in his lab, and Beatriz Orihuela de Diaz for her technical assistance and procurement of adult colonies. We are grateful to Robert Smidt (California Polytechnic State University) for lending his expertise on statistical analysis. Two anonymous reviewers provided thoughtful comments improving this manuscript. Funding was provided by the National Science Foundation (Grant \# IBN-0130634, awarded to D.E. Wendt), the Office of Naval Research (N00014-02-093, awarded to D.E. Wendt) and Cal Poly Student Fees.

\section{References}

Aitkenhead-Peterson JA, McDowell WH, Neff JC (2003) Sources, production, and regulation of allocthonous dissolved 
organic matter inputs to surface waters. In: Findlay SEG, Sinsabaugh RL (eds) Aquatic ecosystems: interactivity of dissolved organic matter. Academic, San Diego, pp 25-70

Armstrong FAJ, Tibbitts S (1968) Photochemical combustion of organic matter in sea water, for nitrogen, phosphorous and carbon determination. J Mar Biolog Assoc UK 48:143-152

Armstrong FAJ, Williams PM, Strickland DH (1966) Photo-oxidation of organic matter in sea water by ultra-violet radiation, analytical and other applications. Nature 211:481-483

Azam F, Hodson RE (1977) Size distribution and activity of marine microheterotrophs. Limnol Oceanogr 22:492-501

Beattie J, Bricker C, Garvin D (1961) Photolytic determination of trace amounts of organic material in water. Anal Chem 33:1890-1892

Ben-David-Zaslow R, Benayahu Y (2000) Biochemical composition, metabolism, and amino acid transport in planula-larvae of the soft coral Heteroxenia fuscescens. J Exp Zool 287:401-412

Benner R (2002) Chemical composition and reactivity. In: Hansell DA, Carlson CA (eds) Biogechemistry of marine dissolved organic matter. Academic, San Diego, pp 59-90

Benner R (2003) Molecular indicators of the bioavailability of dissolved organic matter. In: Findlay SEG, Sinsabaugh RL (eds) Aquatic ecosystems: interactivity of dissolved organic matter. Academic, San Diego, pp 121-137

Best MA, Thorpe JP (1986) Effects of food particle concentration on feeding current velocity in six species of marine Bryozoa. Mar Biol 93:255-262

Carlson CA (2002) Production and removal processes. In: Hansell DA, Carlson CA (eds) Biogeochemistry of dissolved organic matter in the ocean. Academic, San Diego, pp 91-151

Crawford CC, Hobbie JE, Webb KL (1974) The utilization of dissolved free amino acids by estuarine microorganisms. Ecology 55:551-563

Ferguson JC (1967) An autoradiographic study of the utilization of free exogenous amino acids by starfishes. Biol Bull $133: 317-329$

Ferguson JC (1980a) The non-dependency of a starfish on epidermal uptake of dissolved organic matter. Comp Biochem Physiol 66A:461-465

Ferguson JC (1980b) Fluxes of dissolved amino acids between sea water and Echinaster. Comp Biochem Physiol 65A:291-295

Ferguson JC (1982) A comparative study of the net metabolic benefits derived from the uptake and release of free amino acids by marine invertebrates. Biol Bull 162:1-17

Gatti S, Brey T, Müller WEG, Heilmayer O, Holst G (2002) Oxygen microoptodes: a new tool for oxygen measurements in aquatic animal ecology. Mar Biol 140:1075-1085

Jaeckle WB (1994) Rates of energy consumption and acquisition by lecithtrophic larvae of Bugula neritina (Bryozoa: Cheilostomata). Mar Biol 119:517-523

Jaeckle WB (1995) Transport and metabolism of alanine and palmitic acid by field-collected larvae of Tedania ignis (Porifera, Demospongiae): estimated consequences of limited label translocation. Biol Bull 189:159-167

Jaeckle WB, Manahan DT (1989) Feeding by a "nonfeeding" larva: uptake of dissolved amino acids from seawater by lecithotrophic larvae of the gastropod Haliotis rufescens. Mar Biol 103:87-94

Jørgensen CB (1976) August Pütter, August Krogh, and modern ideas on the use of dissolved organic matter in aquatic environments. Biol Rev 51:291-328

Kirchman DL (2003) The contribution of monomers and other low molecular weight compounds to the flux of DOM in aquatic ecosystems. In: Findlay SEG, Sinsabaugh RL (eds) Aquatic ecosystems: interactivity of dissolved organic matter. Academic, San Diego, pp 217-241
Klimant I, Meyer V, Kühl M (1995) Fiber-optic microsensors, a new tool in aquatic biology. Limnol Oceanogr 40:1159-1165

Maldanado M, Young CM (1999) Effects of the duration of larval life on postlarval stages of the demosponge Sigmadocia caerulea. J Exp Mar Biol Ecol 232:9-21

Manahan DT (1983) The uptake and metabolism of dissolved amino acids by bivalve larvae. Biol Bull 164:236-250

Manahan DT (1990) Adaptations by invertebrate larvae for nutrient acquisition from seawater. Am Zool 30:147-160

Manahan DT, Wright SH, Stephens GC, Rice MA (1982) Transport of dissolved amino acids by the mussel, Mytilus edulis: demonstration of net uptake from natural seawater. Science 215:1253-1255

Marsh AG, Manahan DT (1999) A method for accurate measurements of the respiration rates of marine invertebrate embryos and larvae. Mar Ecol Prog Ser 184:1-10

Neter J, Wasserman W, Kutner MH (1985) Applied linear statistical models: regression, analysis of variance, and experimental designs, 2nd edn. Richard D. Irwin, Inc, Illinois

Pechenik JA, Cerulli TR (1991) Influence of delayed metamorphosis on survival, growth, and reproduction of the marine polychaete Capitella sp. I. J Exp Mar Biol Ecol 151:17-27

Shick JM (1975) Uptake and utilization of dissolved glycine by Aurelia aurita scyphistomae: temperature effects on the uptake process; nutritional role of dissolved amino acids. Biol Bull 148:117-140

Shilling FM, Manahan DT (1994) Energy metabolism and amino acid transport during early development of Antarctic and temperate echinoderms. Biol Bull 187:398-407

Sokal RR, Rohlf FJ (1995) Biometry: the principles and practice of statistics in biological research, 3rd edn. W.H. Freeman and Co., New York

Stephens GC (1962) Uptake of organic material by aquatic invertebrates. I. Uptake of glucose by the solitary coral, Fungia scutaria. Biol Bull 123:648-659

Stephens GC (1988) Epidermal amino acid transport in marine invertebrates. Biochim Biophys Acta 947:113-138

Stephens GC, Schinske RA (1961) Uptake of amino acids by marine invertebrates. Limnol Oceanogr 6:175-181

Strathman MF (1987) Reproduction and development of marine invertebrates of the northern Pacific coast: data and methods for the study of eggs, embryos, and larvae. University of Washington Press, Seattle

Weast RC, Astle MJ (1980) CRC handbook of chemistry and physics, 61st edn. CRC Press, Boca Raton

Wendt DE (1996) Effect of larval swimming duration on success of metamorphosis and size of the ancestrular lophophore in Bugula neritina (Bryozoa). Biol Bull 191:224-233

Wendt DE (1998) Effect of larval swimming duration on growth and reproduction of Bugula neritina (Bryozoa) under field conditions. Biol Bull 195:126-135

Wendt DE (2000) Energetics of larval swimming and metamorphosis in four species of Bugula (Bryozoa). Biol Bull 198:346-356

Wendt DE, Woollacott RM (1995) Induction of larval settlement by $\mathrm{KCl}$ in three species of Bugula (Bryozoa). Invert Biol 114:345-351

Williams PJlB, Berman T, Holm-Hansen O (1976) Amino acid uptake and respiration by marine heterotrophs. Mar Biol 35:41-47

Woollacott RM, Pechenik JA, Imbalzano KM (1989) Effects of duration of larval swimming period on early colony development in Bugula stolonifera (Bryozoa: Cheilostomata). Mar Biol 102:57-63 